\title{
Impact of Diverse Ion Channels on Regulatory $T$ Cell Functions
}

\author{
Laura Vinnenberg ${ }^{\mathrm{a}}$ Stefanie Bock ${ }^{\mathrm{a}} \quad$ Petra Hundehege $^{\mathrm{a}} \quad$ Tobias Ruck $^{\mathrm{b}} \quad$ Sven G. Meuth ${ }^{\mathrm{b}}$ \\ aDepartment of Neurology, Institute of Translational Neurology, University Hospital Muenster, \\ Muenster, Germany, bepartment of Neurology, University Hospital Duesseldorf, Duesseldorf, Germany
}

\section{Key Words}

Tregs $\bullet$ Ion channels $\cdot \mathrm{CRAC} \cdot \mathrm{Kv} 1.3 \cdot \mathrm{KCa} 3.1 \cdot \mathrm{TRP} \cdot \mathrm{P} 2 \mathrm{X} \cdot \mathrm{VRAC}$

\begin{abstract}
The population of regulatory $T$ cells (Tregs) is critical for immunological self-tolerance and homeostasis. Proper ion regulation contributes to Treg lineage identity, regulation, and effector function. Identified ion channels include $\mathrm{Ca}^{2+}$ release-activated $\mathrm{Ca}^{2+}$, transient receptor potential, P2X, volume-regulated anion and $\mathrm{K}^{+}$channels $\mathrm{Kv} 1.3$ and $\mathrm{KCa} 3.1$. Ion channel modulation represents a promising therapeutic approach for the treatment of autoimmune diseases such as rheumatoid arthritis and multiple sclerosis. This review summarizes studies with gene-targeted mice and pharmacological modulators affecting Treg number and function. Furthermore, participation of ion channels is illustrated and the power of future research possibilities is discussed.

\section{Introduction}

Regulatory $\mathrm{T}$ cells (Tregs) play a central role in maintaining self-tolerance. They suppress unwanted or excessive immune reactions by limiting the activity of effector immune cells. Defects in Treg development, stability, or the suppressive mechanisms of Tregs are associated with several autoimmune diseases, including multiple sclerosis and rheumatoid arthritis [1-3]. For these diseases, Treg frequency is a well-characterized parameter, and fluctuation patterns due to disease phase and treatment regimen have been determined [4]. Also, a rare immune dysregulation disorder (polyendocrinopathy, enteropathy, X-linked (IPEX)) is linked to mutations in forkhead box protein 3 (FoxP3), the major transcription factor of Tregs [5]. Tregs have been highlighted as critical contributors to immune tolerance breakdown in autoimmunity and represent promising therapeutic targets. Hence, novel therapies aim to strengthen Treg generation and stability [6]. However, the regulation of Tregs has its downsides. An increased Treg expansion might support pathological events since immune cell action against tumor cells is suppressed [7]. To fully exploit the therapeutic 
potential of Tregs, a detailed understanding of molecular mechanisms in health and disease is essential.

FoxP3 is strongly expressed and considered the most prominent marker for Tregs [8]. Tregs belong to the CD4 ${ }^{+} \mathrm{T}$ cell compartment and are characterized by high CD25 and low CD127 expression in humans Treg. Thymus-derived (tTregs) and peripherally-induced Tregs (pTregs) can be distinguished, while further discrimination of Treg subpopulations is controversial [9]. tTregs have a high affinity for their antigen and are mainly involved in selftolerance. pTregs develop from conventional T cells (Tconv) during an immune response, cooperatively contributing to immune homeostasis [10].

The suppressive mechanisms of Tregs have not been fully elucidated yet, however an interplay of different milieu adapting mechanisms is likely. On the one hand, Tregs inhibit effector immune cells by cell-cell contact via surface-bound receptors, e.g. cytotoxic T-lymphocyte antigen 4 (CTLA-4). On the other hand, Tregs release messenger substances, including the anti-inflammatory cytokines interleukin 10 (IL-10) and transforming growth factor-beta (TGF- $\beta$ ), in response to T cell receptor (TCR) stimulation [11]. Also, a cytotoxic effect by perforin and granzyme B secretion, disruption of metabolic processes, and competition for signals from antigen-presenting cells (APC) are discussed in this context [12-14].

Far less is known about regulatory mechanisms in Tregs themselves. The crucial role of ion channels for differentiation, maintenance, and activation immune cells has been strengthened in recent years. Ion channels participate in membrane potential regulation, calcium signaling pathways, and effector functions of immune cells $[15,16]$. Furthermore, the membrane potential of $\mathrm{CD} 4^{+} \mathrm{T}$ cells is a subset-specific feature. Different subpopulations are characterized by specific membrane potentials that might be based on subset-specific ion channel expression or activity [17]. Understanding the distinct role of those ion channels might help to elucidate Treg regulatory mechanisms. Moreover, the dynamic pharmacological modulation of Treg differentiation and function by targeting ion channels might open new therapeutic avenues.

Therefore, the present review deals with the critical role of ion channels in controlling Treg lineage identity, regulation, and effector function. We summarize the literature focusing on gene-targeted mice and channel modulators. The role of the $\mathrm{Ca}^{2+}$ release-activated $\mathrm{Ca}^{2+}$ (CRAC) channel in $\mathrm{Ca}^{2+}$ regulation and the significant contribution of the $\mathrm{K}^{+}$channels $\mathrm{Kv} 1.3$ and KCa3.1 to the membrane potential are discussed. Moreover, we describe how transient receptor potential (TRP), anion (VRAC), and P2X channels affect Treg function.

\section{Ca2+ channels}

\section{CRAC channels}

Calcium is known as an essential second messenger for the development and function of immune cells and is engaged in Treg differentiation. The depletion of intracellular calcium stores entails store-operated calcium entry (SOCE). The stromal interaction molecule (STIM1) is located in the membrane of the endoplasmic reticulum (ER) and senses intraluminal calcium. Under ER calcium depletion, STIM1 relocates to the plasma membrane and activates CRAC channels. The pore-forming subunit Orai, with the three known homologs Orai1, Orai2, and Orai3, mediates robust and sustained $\mathrm{Ca}^{2+}$ influx in human $\mathrm{T}$ cells.

Human $\mathrm{T}$ cell subtypes show small but consistent differences in their $\mathrm{Ca}^{2+}$ signatures. Interestingly, the most prominent SOCE response was detected for human Tregs $[18,19]$. Human Tregs exhibit lower expression levels of Orai2 compared to Tconv [18]. Surprisingly, a correlation between low Orai2 expression levels and increased SOCE magnitude was independently confirmed: both downregulation of Orai2 in Jurkat $\mathrm{T}$ cells and murine genetic Orai2 deletion resulted in enhanced SOCE $[20,21]$. In contrast, Orai1 deficiency led to plummeting SOCE and CRAC currents in mice [21]. However, the overall importance of Orai 1 and Orai 2 is controversial. It was observed that Orai1 and Orai2 compete for limited 


\section{Cellular Physiology Cell Physiol Biochem 2021;55(S3):145-156 \\ \begin{tabular}{ll|l} 
and Biochemistry $\begin{array}{l}\text { DOl.33594/000000375 } \\
\text { Published online: } 28 \text { May } 2021\end{array}$ & $\begin{array}{l}\text { O } 2021 \text { The Author(s). Published by } \\
\text { Cell Physiol Biochem Press GmbH\&Co. KG }\end{array}$
\end{tabular} \\ Vinnenberg et al.: Ion Channels on Regulatory T Cells}

STIM1 molecules essential for activation under physiological conditions, and Orai2-STIM1 complexes conduct much smaller currents compared to Orai1-STIM1 complexes [22, 23]. Nevertheless, Treg functions of Orai1 and STIM1 deficient mice were only moderately impaired, indicating that the remaining $\mathrm{Ca}^{2+}$ influx, mediated by Orai2/3 and STIM2, can compensate for this defect [24]. Also, combined (but not individual) deletion of Orai1 and Orai 2 was reflected in decreased Treg cell numbers in mice [21]. Moreover, STIM1/2 deletion resulted in impaired Treg frequencies and reduced the suppressive function [25, 26]. The abolished $\mathrm{Ca}^{2+}$ signal prevented differentiation into effector, tissue-resident, and follicular Tregs [26-28]. This defect was associated with both impaired IL-2 sensing and nuclear translocation of the transcription factors NFAT and NF- $\kappa B$, both necessary for Treg development, stability and function [25, 27, 29, 30]. However, various other target genes, molecules, and pathways are also regulated by SOCE [31-33]. Deficiency of STIM1 and Orai1 in humans was associated with severe combined immune deficiency (SCID), autoimmunity, and reduced Treg numbers [34, 35].

These data highlight the essential role of the CRAC channel-controlled transcriptional network affecting Treg differentiation, expansion, and homeostasis. Yet, the underlying molecular mechanisms are not fully understood. Interestingly, inhibition of Calcineurin potentially blocked NFAT mediated $\mathrm{T}$ cell proliferation and FoxP3 expression in tTregs and pTregs. In contrast, the CRAC channel inhibitor ORAIci only affected pTregs. This way suggesting the existence of an independent $\mathrm{Ca}^{2+}$-permissive channel in tTregs, that might compensate for abolished CRAC signaling [24]. Thus, the Treg $\mathrm{Ca}^{2+}$ signature might not be solely dependent on CRAC genes, which gives evidence for other yet unidentified channels such as TRPC3 or TRPM4 in Tregs [18].

\section{$\mathrm{K}^{+}$channels}

$\mathrm{K}^{+}$channels mediate continuous efflux of $\mathrm{K}^{+}$ions and thus hyperpolarize the membrane potential. The best characterized $\mathrm{K}^{+}$channels, predominantly controlling the membrane potential in Tregs, are the voltage-activated $\mathrm{K}^{+}$channel $\mathrm{Kv} 1.3$ and the $\mathrm{Ca}^{2+}$ activated $\mathrm{K}^{+}$ channel KCa3.1 (or KCNN4, IKCa ${ }^{2+}$, SK4). The Kv1.3 channel is a homotetramer, and each $\alpha$-subunit comprises six transmembrane domains (S1-S6). The voltage sensor in S4 detects depolarization, followed by a conformational change that opens the channel [36, 37]. In contrast, the tetrameric KCa3.1 channel is sensitive to intracellular $\mathrm{Ca}^{2+}$ concentration $\left(\left[\mathrm{Ca}^{2+}\right]_{\mathrm{i}}\right)$ changes [38]. $\mathrm{Ca}^{2+}$ responsivity is imparted by calmodulin, which is constitutively bound to the KCa3.1 channel. Upon $\mathrm{Ca}^{2+}$ binding, calmodulin induces conformational changes and evokes channel opening [39].

By regulating the membrane potential, both channels set the threshold for calcium influx and are involved in antigenic activation and proliferation of $T$ cells $[15,40]$. Interestingly, Kv1.3 and KCa3.1 are expressed at different levels in T cell subtypes and specific states of activation. This expression pattern indicates adaption mechanisms to highly specialized tasks in immune response regulation.

However, study results are controversial and partly contradictory. For example, high Kv1.3 channel activity has been implicated in the pathogenesis of autoimmune diseases, including multiple sclerosis, type- 1 diabetes mellitus, and rheumatoid arthritis $[41,42]$. Comparative expression analysis revealed that Tregs of MS patients express fewer Kv1.3 channels than naive cells, while this difference was not found in healthy donors [43]. Accordingly, modulation of Kv1.3 supports a protective channel function: upregulation resulted in boosted Treg proliferation, and experiments with the high-affinity Kv1.3 antagonist eplerenone revealed diminished TGF- $\beta$ and IL-10 secretion in treated Tregs [44]. Furthermore, inhibition of Kv1.3 in human lymphocytes led to decreased $\mathrm{Ca}^{2+}$ entry with larger defects monitored in $\mathrm{CD}^{+}$than $\mathrm{CD}^{+} \mathrm{T}$ cells [45]. This indicates Kv1.3 as a selective target in $\mathrm{CD} 4^{+} \mathrm{T}$ cells. 
In contrast to $\mathrm{Kv} 1.3$, inhibition of the $\mathrm{KCa} 3.1$ channel reduced the $\mathrm{Ca}^{2+}$ influx in $\mathrm{CD} 4{ }^{+}$ $\mathrm{T}$ cells to a lower extent than in $\mathrm{CD}^{+} \mathrm{T}$ cells [45]. KCa3.1 channel activity was shown to be necessary for TCR-stimulated $\mathrm{Ca}^{2+}$ influx, and differential expression patterns are known. Thus, only in the course of activation, T cells upregulate KCa3.1 channel expression [46]. Interestingly, dominant KCa3.1 expression was monitored in T helper 1 (Th1) cells, and their action is closely associated with autoimmunity [47, 48]. Genetic KCa3.1 depletion did not reduce the beneficial function of Tregs in mice. To this end, KCa3.1 antagonists have therapeutic potential for inhibiting autoimmune-inducing Th1, while KCa3.1 inhibition does not impair Treg function $[45,49]$.

\section{Other channels}

\section{P2X purinoreceptor channels}

The P2X family of ionotropic, adenosine triphosphate (ATP) gated cation channels comprises seven subunits (P2X1-7), and, interestingly, P2X7 is expressed by most cells of the immune system [50]. Binding of extracellular ATP causes a conformational change in P2X purinoreceptor channels and allows the flow of $\mathrm{Ca}^{2+}, \mathrm{Na}^{+}$, and $\mathrm{K}^{+}$ions $[51,52]$. While the inwardly rectifying current flows, the membrane depolarizes and induces additional $\mathrm{Ca}^{2+}$ influx via voltage gated $\mathrm{Ca}^{2+}$ channel and thus, NFAT activation and IL-2 synthesis in $\mathrm{T}$ cells [53]. T cells respond to ATP secreted by other cells, and, also, an autocrine secretion of ATP via pannexin- 1 hemichannels occurs $[54,55]$. This control mechanism might ensure $\mathrm{Ca}^{2+}$ signaling by fortifying weak TCR signals [56].

The contribution of P2X7 to Treg stability and function was investigated using (ant) agonists and knockout mice. $P 2 r x 7$, the gene encoding the P2X7 receptor, is a Treg signature gene, and it has been postulated that P2X7 triggers ATP-mediated cell death in Tregs $[57,58]$. Increased P2X7 stimulation with BzATP of Tregs was shown to diminish FoxP3 expression but increased levels of Th17 specific transcription factors [59]. By mediating Treg instability and conversion to Th17 cells, ATP/P2X7 signaling appeared to be proinflammatory [60]. Furthermore, the potential to activate the inflammasome was reported [61]. Compared to Tconv, Tregs produced substantially lower amounts of ATP after TCR stimulation, and the ectonucleotidases CD39 and CD73 converted ATP to adenosine, a suppressor of leukocyte activation [54,62]. In contrast, ATP also revealed anti-inflammatory properties in some experiments. The suppressive activity of Tregs was enhanced under ATP exposure, and P2X7 receptor inhibition diminished suppressor function [63]. In T cells, P2X1 and P2X4 were implicated in $\mathrm{Ca}^{2+}$ influx, but only a few experiments investigated their role in Treg function [55]. P2X1 inhibition of Tregs with NF-449 did not affect activation or suppressive capacity [64].

The influence of P2X channels on the developmental and immunosuppressive program of Tregs needs further investigation to uncover the underlying molecular mechanisms and to unveil the connections between different study outcomes. Although examining all isoforms (P2X1-7) seems worthwhile, a specific role of P2X7 in Treg is likely.

\section{TRP channels}

The superfamily of TRP channels comprises integral membrane proteins that function as ion channels. TRP channels are widely expressed non-selective cation permeable channels acting as polymodal sensors and are involved in many physiological and pathological pathways. Based on their protein homology and domain structure, six TRP subfamilies were classified in mammals, including TRPC (canonical), TRPV (vanilloid), TRPM (melastatin), TRPP (polycystin), TRPML (mucolipin), and TRPA (ankyrin) [65, 66]. The knowledge of TRP functions in immune cells has been continuously expanded in recent years. For example, TRPM4 mediated $\mathrm{V}_{\mathrm{m}}$ depolarization prevents $\mathrm{Ca}^{2+}$ overload in response to SOCE [67]. Moreover, the TRP channel contribution to cytokine production was detected $[68,69]$. 
Although the knowledge on TRP channel function in immune cells is growing, further detailed research is required.

The specified role of TRP channels in subpopulations such as Tregs is of interest. Genetic Trpm $4 \%$ in mice did not alter the number of Tregs, expression levels of activation markers (CD25, CD69), or cytokine production [70]. In contrast, initial evidence for an important role of TRPC5 in the suppressive function of Tregs in autoimmunity was provided. Treg mediated TRPC5 activity was identified as a mechanism potentially contributing to suppression of experimental autoimmune encephalomyelitis in knockout mice lacking gangliotetraose gangliosides [71-73]. Also, the TRPM7 channel was identified as a promising target in inflammatory disorders, e.g., graft-versus-host disease (GvHD). TRPM7 is a bifunctional protein operating as a cation channel and serine-threonine kinase [74]. Trpm $7 \%$ mice are embryonically lethal, but modulating the enzymatic activity might harbor pharmacological potential [75]. Inactivation of its catalytic activity via K1646R mutation in mice did not affect differentiation of Tregs but reduced differentiation of proinflammatory Th17 [76]. To this end, identifying TRPM7 kinase substrates and inhibitors represents a promising strategy to treat inflammatory disorders.

\section{Volume-regulated anion channel (VRAC)}

To compensate intra- and extracellular osmotic variability, cells adapt their cell volume. Within this process, the volume-regulated anion channel (VRAC) was identified as a key player. VRAC is ubiquitously expressed in vertebrate cells, nearly inactive under resting conditions, and activated by hypotonic swelling. VRAC mediated $\mathrm{Cl}^{-}$efflux provokes the release of osmotically absorbed water and thereby counteracts swelling [77-79]. Using a genome-wide screening of small interfering RNA, the leucine-rich repeat-containing protein 8A (LRRC8A alias SWELL1) was identified as an essential, potentially pore-forming component of the heterooligomeric VRAC $[80,81]$. Characterization revealed increased expression of LRRC8A on T cells compared to other immune cells, and $\mathrm{LrCC}_{\mathrm{C}} \mathrm{C} \mathrm{O}^{-}$mice gave evidence for the special functioning of LRRC8A in Tregs. While the number of Tconv was reduced, Treg number and density were increased [82]. However, the molecular mechanism leading to this remarkable difference was not uncovered so far.

Fig. 1. Ion channels in Tregs. The depletion of intracellular $\mathrm{Ca}^{2+}$ stores in the endoplasmatic reticulum (ER) is mediated via the inositol-1,4,5-trisphosphate receptor $\left(\mathrm{IP}_{3} \mathrm{R}\right)$. The rising intracellular $\mathrm{Ca}^{2+}$ concentration activates the stromal interaction molecule 1 (STIM1) and STIM2, which subsequently relocate to the plasma membrane and activate the $\mathrm{Ca}^{2+}$ releaseactivated $\mathrm{Ca}^{2+}$ channel (CRAC) formed by Orai homologs 1-3. In addition, non- $\mathrm{Ca}^{2+}$-selective transient receptor potential

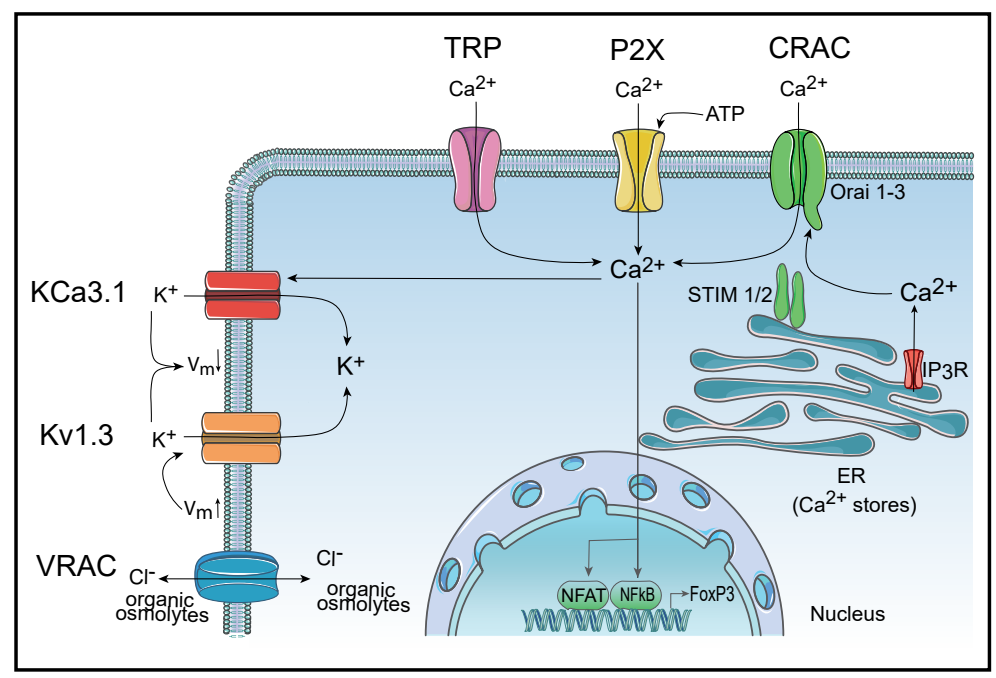
(TRP) and adenosine triphos-

phate (ATP) activated P2X channels mediate $\mathrm{Ca}^{2+}$ entry. Sustained $\mathrm{Ca}^{2+}$ influx ensues nuclear translocation of transcription factors such as nuclear factor of activated T cells (NFAT) and nuclear factor- $\kappa \mathrm{B}(\mathrm{NF}-\kappa \mathrm{B})$. Also, $\mathrm{Ca}^{2+}$ provokes opening of the $\mathrm{K}^{+}$channel $\mathrm{KCa} 3.1$. KCa3.1 regulates the membrane potential $\left(\mathrm{V}_{\mathrm{m}}\right)$, together with the voltage-activated Kv1.3. The volume-regulated anion channel (VRAC) mediates $\mathrm{Cl}^{-}$efflux, provokes the release of osmotically absorbed water, and thereby counteracts swelling. 


\section{Cellular Physiology Cell Physiol Biochem 2021;55(S3):145-156

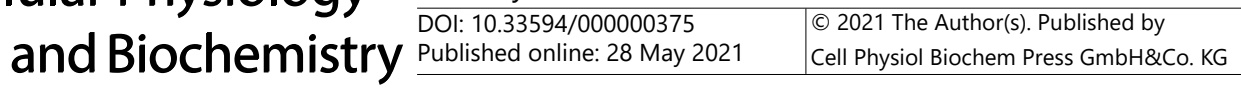 \\ Vinnenberg et al.: Ion Channels on Regulatory T Cells}

Table 1. Ion channels of regulatory $\mathrm{T}$ cells and associated diseases. This table gives an overview of ion channels involved in Treg differentiation and function and the associated diseases. CRAC channel activity is best characterized in mouse models, as well as in humans. In contrast, the understanding of other channels is limited, and the investigation of their special functions in Tregs has just started. However, the current state of research confirms that a diverse set of ion channels is involved in Treg lineage identity

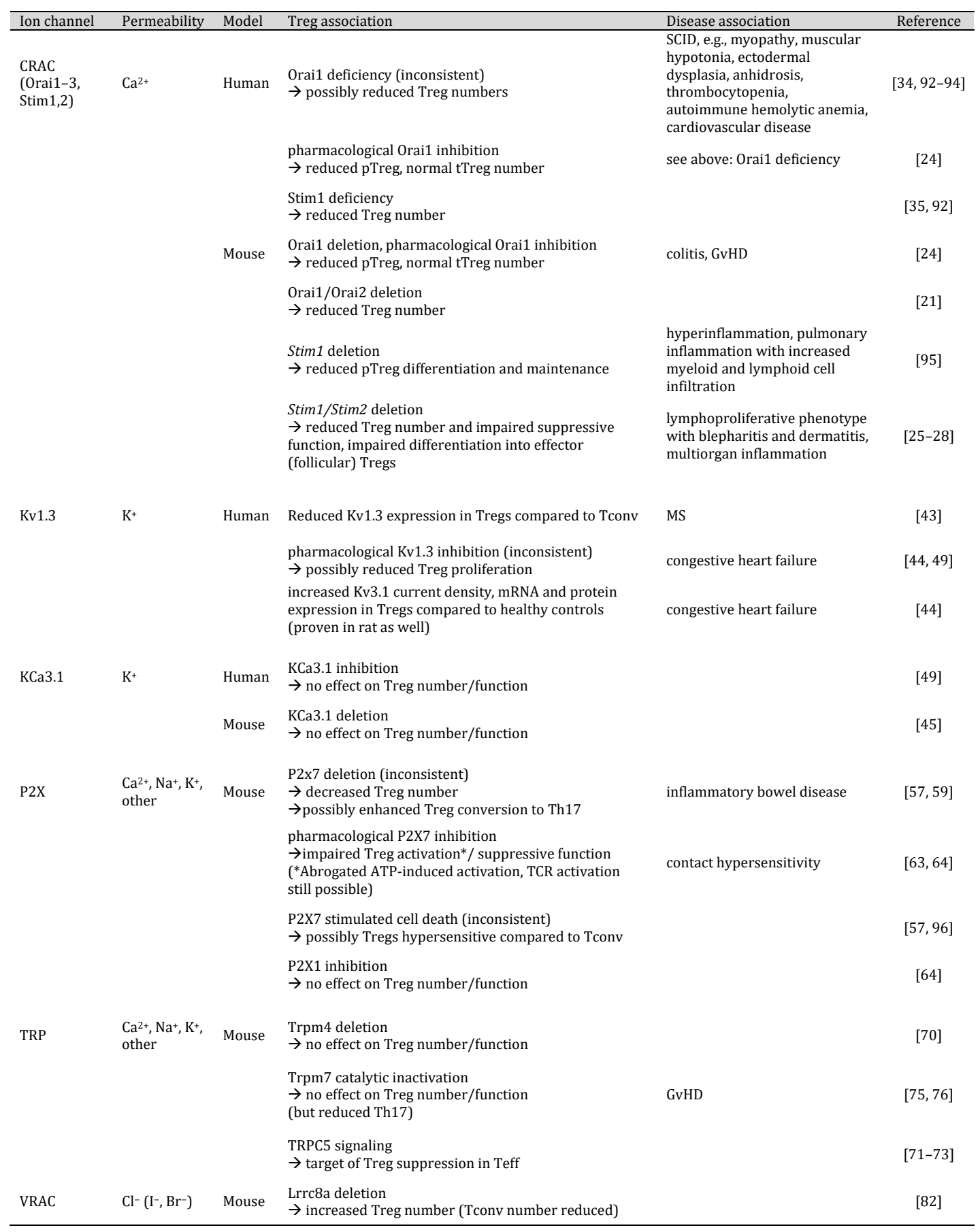




\section{Cellular Physiology Cell Physiol Biochem 2021;55(S3):145-156 \begin{tabular}{l|l|l|l} 
Dol: 10.33594/000000375 & O 2021 The Author(s). Published by \\
and Biochemistry Published online: 28 May 2021 & Cell Physiol Bichem Press Gmbsco
\end{tabular} \\ Vinnenberg et al.: Ion Channels on Regulatory T Cells}

\section{Conclusion}

The study of ion homeostasis in Tregs and its significance for their protective function has received rising attention in recent years (Fig. 1). The participation of CRAC, Kv1.3, KCa3.1, and VRAC channels in Treg signaling have already been reported. Nevertheless, the detailed mechanisms and differentiation from other immune cells are not fully understood. Most studies have focused on CRAC mediated $\mathrm{Ca}^{2+}$ signaling, while there is growing evidence for a specialized contribution of voltage-dependent $\mathrm{Ca}^{2+}$ and $\mathrm{K}^{+}$channels and the $\mathrm{Ca}^{2+}$ extrusion pump PMCA $[83,84]$. Next to the already elucidated channels, Tregs are named as further candidates in several reviews dealing with ion channels, known channelopathies, and associated diseases in all immune cells (Table 1) $[85,86]$. However, in comparison to conventional $\mathrm{T}$ cells $(\sim-47 \mathrm{mV})$, Tregs reveal a hyperpolarized membrane potential around $-70 \mathrm{mV}$, suggesting additional or altered ion fluxes [11]. As the resting membrane potential of a cell is due to the outward diffusion of potassium ions, the closer examination of voltage- and calcium-gated $\mathrm{K}_{2 \mathrm{P}}$ channels (e.g., TRESK and TASK subfamilies) in Tregs could be worthwhile [87]. Accordingly, an in-silico model of human T cell electrophysiological behavior takes the contribution of further ion channels into account and highlights their impact on physiological and pathological conditions [88]. In this context, the importance of locally restricted ion channels and redistribution depending on the activation status was reported [89-91]. Hence, ion channel modulation in Tregs has a substantial therapeutic potential for autoimmune diseases. Identifying ion channel distribution patterns and potent (ant)agonists is of outstanding relevance for further studies.

Last but not least, little attention has been paid to $\mathrm{H}^{+}$mediated regulation of $\mathrm{pH}$ and the roles of $\mathrm{Mg}^{2+}$ and $\mathrm{Zn}^{2+}$ as cofactors and second messengers. This indicates that research on the impact of diverse ion channels on Treg function is just at a starting point, and major challenges remain. Also, understanding specific ion channel expression frequencies and patterns in Tregs represents a powerful approach to gain new insights on immunological tolerance and pathophysiological participation in immune diseases.

\section{Acknowledgements}

\section{Author Contributions}

S.M. and P.H. devised the main concept and structure of the review. L.V. collected relevant papers to summarize, interpret and discuss the current state of research regarding the impact of diverse ion channels on regulatory T cell functions. L.V. wrote the manuscript with support of critical input from S.M. and P.H. All authors critically revised the paper and certified the final version of the paper.

Funding

This work was supported by the Deutsche Forschungsgemeinschaft (DFG, GRK 2515, "Chemical biology of ion channels").

\section{Disclosure Statement}

The authors have no conflicts of interest to declare.

\section{References}

1 Buckner JH: Mechanisms of impaired regulation by CD4(+)CD25(+)FOXP3(+) regulatory T cells in human autoimmune diseases. Nat Rev Immunol 2010;12:849-859. 
2 Dejaco C, Duftner C, Grubeck-Loebenstein B, Schirmer M: Imbalance of regulatory T cells in human autoimmune diseases. Immunology 2006;117:289-300.

3 Shevach EM: Foxp3+ T Regulatory Cells: Still Many Unanswered Questions-A Perspective After 20 Years of Study. Front Immunol 2018;9:1048.

4 Grant CR, Liberal R, Mieli-Vergani G, Vergani D, Longhi MS: Regulatory T-cells in autoimmune diseases: challenges, controversies and--yet--unanswered questions. Autoimmun Rev 2015;14:105-116.

5 Torgerson TR, Ochs HD: Immune dysregulation, polyendocrinopathy, enteropathy, X-linked: forkhead box protein 3 mutations and lack of regulatory T cells. J Allergy Clin Immunol 2007;120:744-750.

6 Boehmer H von, Daniel C: Therapeutic opportunities for manipulating T(Reg) cells in autoimmunity and cancer. Nat Rev Drug Discov 2013;12:51-63.

7 Facciabene A, Motz GT, Coukos G: T-regulatory cells: key players in tumor immune escape and angiogenesis. Cancer Res 2012;72:2162-2171.

8 Seddiki N, Santner-Nanan B, Martinson J, Zaunders J, Sasson S, Landay A, Solomon M, Selby W, Alexander SI, Nanan R, Kelleher A, Fazekas de St Groth B: Expression of interleukin (IL)-2 and IL-7 receptors discriminates between human regulatory and activated T cells. J Exp Med 2006; 203:1693-1700.

9 Abbas AK, Benoist C, Bluestone JA, Campbell DJ, Ghosh S, Hori S, Jiang S, Kuchroo VK, Mathis D, Roncarolo MG, Rudensky A, Sakaguchi S, Shevach EM, Vignali DAA, Ziegler SF: Regulatory T cells: recommendations to simplify the nomenclature. Nat Immunol 2013;14:307-308.

10 Schmitt EG, Williams CB: Generation and function of induced regulatory T cells. Front Immunol 2013;4:152.

11 Pankratz S, Bittner S, Herrmann AM, Schuhmann MK, Ruck T, Meuth SG, Wiendl H: Human CD4+ HLA-G+ regulatory T cells are potent suppressors of graft-versus-host disease in vivo. FASEB J 2014;28:3435-3445.

12 Caridade M, Graca L, Ribeiro RM: Mechanisms Underlying CD4+ Treg Immune Regulation in the Adult: From Experiments to Models. Front Immunol 2013;4:378.

13 Dendrou CA, Fugger L, Friese MA: Immunopathology of multiple sclerosis. Nat Rev Immunol 2015;15:545558.

14 Miyara M, Sakaguchi S: Natural regulatory T cells: mechanisms of suppression. Trends Mol Med 2007;13:108-116.

15 Cahalan MD, Chandy KG: The functional network of ion channels in T lymphocytes. Immunol Rev 2009;231:59-87.

16 Ehling P, Bittner S, Budde T, Wiendl H, Meuth SG: Ion channels in autoimmune neurodegeneration. FEBS Lett 2011;585:3836-3842.

17 Marek N, Myśliwska J, Raczyńska K, Trzonkowski P: Membrane potential of CD4+ T cells is a subset specific feature that depends on the direct cell-to-cell contacts with monocytes. Hum Immunol 2010;71:666-675.

18 Kircher S, Merino-Wong M, Niemeyer BA, Alansary D: Profiling calcium signals of in vitro polarized human effector CD4 + T cells. Biochim Biophys Acta Mol Cell Res 2018;1865:932-943.

19 Schwarz A, Schumacher M, Pfaff D, Schumacher K, Jarius S, Balint B, Wiendl H, Haas J, Wildemann B: Finetuning of regulatory $\mathrm{T}$ cell function: the role of calcium signals and naive regulatory $\mathrm{T}$ cells for regulatory $\mathrm{T}$ cell deficiency in multiple sclerosis. J Immunol 2013;190:4965-4970.

20 Alansary D, Bogeski I, Niemeyer BA: Facilitation of Orai3 targeting and store-operated function by Orai1. Biochim Biophys Acta 2015;1853:1541-1550.

21 Vaeth M, Yang J, Yamashita M, Zee I, Eckstein M, Knosp C, Kaufmann U, Karoly Jani P, Lacruz RS, Flockerzi V, Kacskovics I, Prakriya M, Feske S: ORAI2 modulates store-operated calcium entry and T cell-mediated immunity. Nat Commun 2017;8:14714.

22 Frischauf I, Muik M, Derler I, Bergsmann J, Fahrner M, Schindl R, Groschner K, Romanin C : Molecular determinants of the coupling between STIM1 and Orai channels: differential activation of Orai1-3 channels by a STIM1 coiled-coil mutant. J Biol Chem 2009;284:21696-21706.

23 Lis A, Peinelt C, Beck A, Parvez S, Monteilh-Zoller M, Fleig A, Penner R: CRACM1, CRACM2, and CRACM3 are store-operated $\mathrm{Ca} 2+$ channels with distinct functional properties. Curr Biol 2007;17:794-800.

24 Jin S, Chin J, Kitson C, Woods J, Majmudar R, Carvajal V, Allard J, Demartino J, Narula S, Thomas-Karyat DA: Natural regulatory $\mathrm{T}$ cells are resistant to calcium release-activated calcium (CRAC/ORAI) channel inhibition. Int Immunol 2013;2:497-506.

25 Oh-Hora M, Yamashita M, Hogan PG, Sharma S, Lamperti E, Chung W, Prakriya M, Feske S, Rao A: Dual functions for the endoplasmic reticulum calcium sensors STIM1 and STIM2 in T cell activation and tolerance. Nat Immunol 2008;9:432-443. 
26 Oh-Hora M, Komatsu N, Pishyareh M, Feske S, Hori S, Taniguchi M, Rao A, Takayanagi H: Agonist-selected $\mathrm{T}$ cell development requires strong $\mathrm{T}$ cell receptor signaling and store-operated calcium entry. Immunity 2013;38:881-895.

27 Vaeth M, Eckstein M, Shaw PJ, Kozhaya L, Yang J, Berberich-Siebelt F, Clancy R, Unutmaz D, Feske S: StoreOperated $\mathrm{Ca}(2+)$ Entry in Follicular T Cells Controls Humoral Immune Responses and Autoimmunity. Immunity2016;44:1350-1364.

28 Vaeth M, Wang YH, Eckstein M, Yang J, Silverman GJ, Lacruz RS, Kannan K, Feske S: Tissue resident and follicular Treg cell differentiation is regulated by CRAC channels. Nat Commun 2019;10:531.

29 Grinberg-Bleyer Y, Oh H, Desrichard A, Bhatt DM, Caron R, Chan TA, Schmid RM, Klein U, Hayden MS, Ghosh S: NF-кB c-Rel Is Crucial for the Regulatory T Cell Immune Checkpoint in Cancer. Cell 2017;170:1096-1108.

30 Oh-Hora M, Rao A: The calcium/NFAT pathway: role in development and function of regulatory T cells. Microbes Infect 2009;11:612-619.

31 Cuadrado E, van den Biggelaar M, Kivit S de, Chen Y-Y, Slot M, Doubal I, Meijer A, van Lier RAW, Borst J, Amsen D: Proteomic Analyses of Human Regulatory T Cells Reveal Adaptations in Signaling Pathways that Protect Cellular Identity. Immunity 2018;48:1046-1059.

32 Levine AG, Arvey A, Jin W, Rudensky A: Continuous requirement for the TCR in regulatory T cell function. Nat Immunol 2014;15:1070-1078.

33 Vahl JC, Drees C, Heger K, Heink S, Fischer JC, Nedjic J, Ohkura N, Morikawa H, Poeck H, Schallenberg S, Rieß D, Hein MY, Buch T, Polic B, Schönle A, Zeiser R, Schmitt-Gräff A, Kretschmer K, Klein L, Korn T, et al.: Continuous $\mathrm{T}$ cell receptor signals maintain a functional regulatory $\mathrm{T}$ cell pool. Immunity2014;4:722-736.

34 Feske S, Gwack Y, Prakriya M, Srikanth S, Puppel SH, Tanasa B, Hogan PG, Lewis RS, Daly M, Rao A: A mutation in Orai1 causes immune deficiency by abrogating CRAC channel function. Nature 2006;441:179185.

35 Picard C, McCarl C-A, Papolos A, Khalil S, Lüthy K, Hivroz C, LeDeist F, Rieux-Laucat F, Rechavi G, Rao A, Fischer A, Feske S: STIM1 mutation associated with a syndrome of immunodeficiency and autoimmunity. N Engl J Med 2009;360:1971-1980.

36 Bezanilla F: How membrane proteins sense voltage. Nat Rev Mol Cell Biol 2008;9:323-332.

37 Cahalan MD, Chandy KG, DeCoursey TE, Gupta S: A voltage-gated potassium channel in human T lymphocytes. J Physiol 1985;358:197-237.

38 Sforna L, Megaro A, Pessia M, Franciolini F, Catacuzzeno L: Structure, Gating and Basic Functions of the Ca2+-activated K Channel of Intermediate Conductance. Curr Neuropharmacol 2008;16:608-617.

39 Fanger CM, Ghanshani S, Logsdon NJ, Rauer H, Kalman K, Zhou J, Beckingham K, Chandy KG, Cahalan MD, Aiyar J:Calmodulin mediates calcium-dependent activation of the intermediate conductance KCa channel, IKCa1. J Biol Chem 1999;274:5746-5754.

40 Lewis RS, Cahalan MD: Potassium and calcium channels in lymphocytes. Annu Rev Immunol 1995;13:623653.

41 Beeton C, Wulff H, Standifer NE, Azam P, Mullen KM, Pennington MW, Kolski-Andreaco A, Wei E, Grino A, Counts DR, Wang PH, LeeHealey CJ, S Andrews B, Sankaranarayanan A, Homerick D, Roeck WW, Tehranzadeh J, Stanhope KL, Zimin P, Havel PJ, et al.: Kv1.3 channels are a therapeutic target for T cellmediated autoimmune diseases. Proc Natl Acad Sci U S A 2006;103:17414-17419.

42 Wulff H, Calabresi PA, Allie R, Yun S, Pennington M, Beeton C, Chandy KG: The voltage-gated Kv1.3 K+ channel in effector memory T cells as new target for MS. J Clin Invest 2003;111:1703-1713.

43 Varga Z, Csepany T, Papp F, Fabian A, Gogolak P, Toth A, Panyi G: Potassium channel expression in human CD4+ regulatory and naïve $T$ cells from healthy subjects and multiple sclerosis patients. Immunol Lett 2009;124:95-101.

44 Shao PP, Liu CJ, Xu Q, Zhang B, Li SH, Wu Y, Sun Z, Cheng LF: Eplerenone Reverses Cardiac Fibrosis via the Suppression of Tregs by Inhibition of Kv1.3 Channel. Front Physiol 2018;9:899.

45 Wang J, Xiang M: Targeting potassium channels Kv1.3 and KC a 3.1: routes to selective immunomodulators in autoimmune disorder treatment? Pharmacotherapy 2013;33:515-528.

46 Ghanshani S, Wulff H, Miller MJ, Rohm H, Neben A, Gutman GA, Cahalan MD, Chandy KG: Up-regulation of the IKCa1 potassium channel during T-cell activation. Molecular mechanism and functional consequences. J Biol Chem 2000;275:37137-37149.

47 Di L, Srivastava S, Zhdanova O, Ding Y, Li Z, Wulff H, Lafaille M, Skolnik EY: Inhibition of the K+ channel KCa3.1 ameliorates T cell-mediated colitis. Proc Natl Acad Sci U S A 2010;107:1541-1546. 
48 Fanger CM, Neben AL, Cahalan MD: Differential Ca2+ influx, KCa channel activity, and Ca2+ clearance distinguish Th1 and Th2 lymphocytes. J Immunol 2000;164:1153-1160.

49 Orbán C, Bajnok A, Vásárhelyi B, Tulassay T, Toldi G: Different calcium influx characteristics upon Kv1.3 and IKCa1 potassium channel inhibition in T helper subsets. Cytometry A 2014;85:636-641.

50 Chen L, Brosnan CF: Regulation of immune response by P2X7 receptor. Crit Rev Immunol 2006;26:499513.

51 North RA: Molecular physiology of P2X receptors. Physiol Rev 2002;82:1013-1067.

52 Surprenant A, North RA: Signaling at purinergic P2X receptors. Annu Rev Physiol 2009;71:333-359.

53 Yip L, Woehrle T, Corriden R, Hirsh M, Chen Y, Inoue Y, Ferrari V, Insel PA, Junger WG: Autocrine regulation of T-cell activation by ATP release and P2X7 receptors. FASEB J 2009;23:1685-1693.

54 Schenk U, Westendorf AM, Radaelli E, Casati A, Ferro M, Fumagalli M, Verderio C, Buer J, Scanziani E, Grassi F: Purinergic control of T cell activation by ATP released through pannexin- 1 hemichannels. Sci Signal 2008;1:ra6.

55 Woehrle T, Yip L, Elkhal A, Sumi Y, Chen Y, Yao Y, Insel PA, Junger WG: Pannexin-1 hemichannel-mediated ATP release together with P2X1 and P2X4 receptors regulate T-cell activation at the immune synapse. Blood 2010;116:3475-3484.

56 Junger WG: Immune cell regulation by autocrine purinergic signalling. Nat Rev Immunol 2011;11:201-212.

57 Aswad F, Kawamura H, Dennert G: High sensitivity of CD4+CD25+ regulatory T cells to extracellular metabolites nicotinamide adenine dinucleotide and ATP: a role for P2X7 receptors. J Immunol 2005;175:3075-3083.

58 Taylor SRJ, Alexander DR, Cooper JC, Higgins CF, Elliott JI: Regulatory T cells are resistant to apoptosis via TCR but not P2X7. J Immunol 2007;178:3474-3482.

59 Schenk U, Frascoli M, Proietti M, Geffers R, Traggiai E, Buer J, Ricordi C, Westendorf AM, Grassi F: ATP inhibits the generation and function of regulatory $\mathrm{T}$ cells through the activation of purinergic P2X receptors. Sci Signal 2011;4:ra12.

60 Louten J, Boniface K, Waal Malefyt R de: Development and function of TH17 cells in health and disease. J Allergy Clin Immunol 2009;123:1004-1011.

61 Di Virgilio: Liaisons dangereuses: P2X(7) and the inflammasome. Trends Pharmacol Sci 2007;28:465-472.

62 Sitkovsky M, Lukashev D, Deaglio S, Dwyer K, Robson SC, Ohta A: Adenosine A2A receptor antagonists: blockade of adenosinergic effects and T regulatory cells. Br J Pharmacol 2008;153:S457-S464.

63 Ring S, Enk AH, Mahnke K: ATP activates regulatory T Cells in vivo during contact hypersensitivity reactions. J Immunol 2010;184:3408-3416.

64 Ring S, Enk AH, Mahnke K: Regulatory T cells from IL-10-deficient mice fail to suppress contact hypersensitivity reactions due to lack of adenosine production. J Invest Dermatol 2011;131:1494-1502.

65 Clapham DE, Runnels LW, Strübing C: The TRP ion channel family. Nat Rev Neurosci 2001;2:387-396.

66 Li H: TRP Channel Classification. Adv Exp Med Biol 2017;976:1-8.

67 Launay P, Cheng H, Srivatsan S, Penner R, Fleig A, Kinet JP: TRPM4 regulates calcium oscillations after T cell activation. Science 2004;306:1374-1377.

68 Bertin S, Aoki-Nonaka Y, Jong PR de, Nohara LL, Xu H, Stanwood SR, Srikanth S, Lee J, To K, Abramson L, Yu T, Han T, Touma R, Li X, González-Navajas JM, Herdman S, Corr M, Fu G, Dong H, et al.: The ion channel TRPV1 regulates the activation and proinflammatory properties of CD $4^{+} \mathrm{T}$ cells. Nat Immunol 2014;15:1055-1063.

69 Melzer N, Hicking G, Göbel K, Wiendl H: TRPM2 cation channels modulate T cell effector functions and contribute to autoimmune CNS inflammation. PLoS One 2012;7:e47617.

70 Schattling B, Steinbach K, Thies E, Kruse M, Menigoz A, Ufer F, Flockerzi V, Brück W, Pongs O, Vennekens R, Kneussel M, Freichel M, Merkler D, Friese MA: TRPM4 cation channel mediates axonal and neuronal degeneration in experimental autoimmune encephalomyelitis and multiple sclerosis. Nat Med 2012;18:1805-1811.

71 Wang J, Lu ZH, Gabius HJ, Rohowsky-Kochan C, Ledeen RW, Wu G: Cross-linking of GM1 ganglioside by galectin- 1 mediates regulatory T cell activity involving TRPC5 channel activation: possible role in suppressing experimental autoimmune encephalomyelitis. The Journal of Immunology 2009;182:40364045. 
72 Wu G, Lu Z-H, André S, Gabius HJ, Ledeen RW: Functional interplay between ganglioside GM1 and crosslinking galectin-1 induces axon-like neuritogenesis via integrin-based signaling and TRPC5-dependent $\mathrm{Ca}^{2+}$ influx. J Neurochem 2016;136:550-563.

73 Wu G, Lu ZH, Gabius HJ, Ledeen RW, Bleich D: Ganglioside GM1 deficiency in effector T cells from NOD mice induces resistance to regulatory T-cell suppression. Diabetes 2011;60:2341-2349.

74 Runnels LW, Yue L, Clapham DE: TRP-PLIK, a bifunctional protein with kinase and ion channel activities. Science 2001;291:1043-1047.

75 Jin J, Desai BN, Navarro B, Donovan A, Andrews NC, Clapham DE: Deletion of Trpm7 disrupts embryonic development and thymopoiesis without altering Mg2+ homeostasis. Science 2008;322:756-760.

76 Romagnani A, Vettore V, Rezzonico-Jost T, Hampe S, Rottoli E, Nadolni W, Perotti M, Meier MA, Hermanns C, Geiger S, Wennemuth G, Recordati C, Matsushita M, Muehlich S, Proietti M, Chubanov V, Gudermann T, Grassi F, Zierler S: TRPM7 kinase activity is essential for T cell colonization and alloreactivity in the gut. Nat Commun 2017;8:1917.

77 Nilius B, Eggermont J, Voets T, Buyse G, Manolopoulos V, Droogmans G: Properties of volume-regulated anion channels in mammalian cells. Prog Biophys Mol Biol 1997;68:69-119.

78 Okada Y: Volume expansion-sensing outward-rectifier Cl- channel: fresh start to the molecular identity and volume sensor. Am J Physiol 1997;273:755-789.

79 Okada Y, Sato K, Numata T: Pathophysiology and puzzles of the volume-sensitive outwardly rectifying anion channel. J Physiol 2009;587:2141-2149.

80 Qiu Z, Dubin AE, Mathur J, Tu B, Reddy K, Miraglia LJ, Reinhardt J, Orth AP, Patapoutian A: SWELL1, a plasma membrane protein, is an essential component of volume-regulated anion channel. Cell 2014;157:447-458.

81 Voss FK, Ullrich F, Münch J, Lazarow K, Lutter D, Mah N, Andrade-Navarro MA, Kries JP von, Stauber T, Jentsch TJ: Identification of LRRC8 heteromers as an essential component of the volume-regulated anion channel VRAC. Science 2014;344:634-638.

82 Kumar L, Chou J, Yee CSK, Borzutzky A, Vollmann EH, Andrian UH von, Park SY, Hollander G, Manis JP, Poliani PL, Geha RS: Leucine-rich repeat containing 8A (LRRC8A) is essential for T lymphocyte development and function. J Exp Med 2014;211:929-942.

83 DeCoursey TE, Chandy KG, Gupta S, Cahalan MD: Voltage-dependent ion channels in T-lymphocytes. J Neuroimmunol 1985;10:71-95.

84 Ritchie MF, Samakai E, Soboloff J: STIM1 is required for attenuation of PMCA-mediated Ca2+ clearance during T-cell activation. EMBO J 2012;31:1123-1133.

85 Feske S, Skolnik EY, Prakriya M: Ion channels and transporters in lymphocyte function and immunity. Nat Rev Immunol 2012;12:532-547.

86 Vaeth M, Feske S: Ion channelopathies of the immune system. Curr Opin Immunol 2018;52:39-50.

87 Eichinger P, Herrmann AM, Ruck T, Herty M, Gola L, Kovac S, Budde T, Meuth SG, Hundehege P: Human T cells in silico: Modelling dynamic intracellular calcium and its influence on cellular electrophysiology. J Immunol Methods 2018;461:78-84.

88 Ehling P, Meuth P, Eichinger P, Herrmann A, Kanyshkova T, Bittner S, Budde T, Meuth SG: Human T cells in silico: Modelling the electrophysiological behaviour of T cells in health and disease. J Neuroimmunol 2014;275:198.

89 Lioudyno MI, Kozak JA, Penna A, Safrina O, Zhang SL, Sen D, Roos J, Stauderman KA, Cahalan MD: Orai1 and STIM1 move to the immunological synapse and are up-regulated during T cell activation. Proc Natl Acad Sci U S A 2008;105:2011-2016.

90 Panyi G, Bagdány M, Bodnár A, Vámosi G, Szentesi G, Jenei A, Mátyus L, Varga S, Waldmann TA, Gáspar R, Damjanovich S: Colocalization and nonrandom distribution of Kv1.3 potassium channels and CD3 molecules in the plasma membrane of human T lymphocytes. Proc Natl Acad Sci U S A 2003;100:25922597.

91 Panyi G, Vámosi G, Bacsó Z, Bagdány M, Bodnár A, Varga Z, Gáspár R, Mátyus L, Damjanovich S: Kv1.3 potassium channels are localized in the immunological synapse formed between cytotoxic and target cells. Proc Natl Acad Sci U S A 2004;101:1285-1290.

92 Feske S: CRAC channelopathies. Pflugers Arch 2010;460:417-435.

93 Lacruz RS, Feske S: Diseases caused by mutations in ORAI1 and STIM1. Ann N Y Acad Sci 2015;1356:45-79. 


\section{Cellular Physiology Cell Physiol Biochem 2021;55(S3):145-156}

\begin{tabular}{ll|l} 
and Biochemistry $10.33594 / 000000375$ & $\begin{array}{l}\text { O 2021 The Author(s). Published by } \\
\text { Published online: } 28 \text { May } 2021\end{array}$ & Cell Physiol Biochem Press GmbH\&Co. KG
\end{tabular}

Vinnenberg et al.: Ion Channels on Regulatory T Cells

94 Lian J, Cuk M, Kahlfuss S, Kozhaya L, Vaeth M, Rieux-Laucat F, Picard C, Benson MJ, Jakovcevic A, Bilic K, Martinac I, Stathopulos P, Kacskovics I, Vraetz T, Speckmann C, Ehl S, Issekutz T, Unutmaz D, Feske S: ORAI1 mutations abolishing store-operated Ca2+ entry cause anhidrotic ectodermal dysplasia with immunodeficiency. J Allergy Clin Immunol 2018;142:1297-1310.

95 Desvignes L, Weidinger C, Shaw P, Vaeth M, Ribierre T, Liu M, Fergus T, Kozhaya L, McVoy L, Unutmaz D, Ernst JD, Feske S: STIM1 controls T cell-mediated immune regulation and inflammation in chronic infection. J Clin Invest 2015;125:2347-2362.

96 Taylor SRJ, Alexander DR, Cooper JC, Higgins CF, Elliott JI: Regulatory T cells are resistant to apoptosis via TCR but not P2X7. J Immunol 2007;178:3474-3482. 